\title{
5-Bromo-3-(3-hydroxyprop-1-ynyl)-2 H-pyran-2-one targets prostate cancer cells by down-regulating inflammation-related genes
}

\author{
Zhao-Yang Wang, Jun-Yong Wang, Jun Zhang, Kai Zhang, Rui Fan and Jun-Hao Niu \\ Department of urology, Zhengzhou Central Hospital Affiliated to Zhengzhou University, Zhengzhou 450 007, China.
}

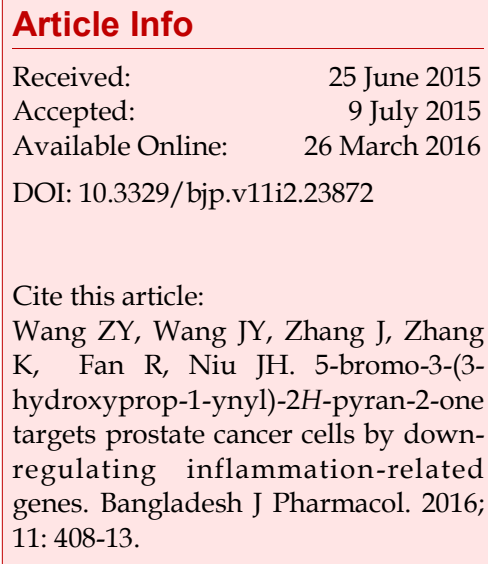

\begin{abstract}
The present study was performed to examine the effect of 5-bromo-3-(3hydroxyprop-1-ynyl)-2H-pyran-2-one (BHP) on the rate of cell proliferation and apoptosis induction in the PC3, human prostate carcinoma cell line. The cell viability was assayed by using sulphorhodamine B staining and apoptosis by annexin $\mathrm{V}$ and flow cytometry analyses. The results revealed that BHP treatment in PC3 cells caused a significant reduction in the rate of cell proliferation in dose- and time-dependent manner. Compared to the untreated cells, the formation of HUVEC tubes was markedly inhibited on treatment with BHP at a concentration of $30 \mu \mathrm{M}$. Further investigation revealed the expression of HMGB1, IL-6 and IL-8, pro-inflammatory cytokines was also inhibited on treatment with BHP. Therefore, BHP treatment plays an important role in inducing apoptosis in the prostrate cells and can be of therapeutic value for the prostate cancer treatment.
\end{abstract}

\section{Introduction}

Prostate cancer, one of the frequent detected causes of mortality in men, accounts for more than 25, 000 deaths in the United States alone every year (Jemal et al., 2010). The treatment strategies generally used for the treatment of prostate cancer in its primary stage include, androgen ablation, surgical removal of the tumor mass and or radiotherapy. However, use of hormones ultimately induces resistance. Therefore, screening of the natural products for investigation and development of the novel treatment strategies for prostate cancer is preferred. In the process of prostate carcinoma cell metastases to adjacent tissues angiogenesis and invasion have been reported to exhibit vital role (Weidner et al., 1993; Wakui et al., 1992). Angiogenesis in prostate carcinoma cells influences the expression levels of p65, VEGF and MMP-9. Another important factor with role in the progress of cancer inflammation which is initiated and regulated by cytokines and chemokines (Lu et al., 2006; Coussens and Werb, 2002).
It has been shown that concentration of IL-6 and IL-8, cytokines is higher in the patients with hormone resistant than in hormone-sensitive disease (Veltri et al., 1999; Pfitzenmaier et al., 2003; Uehara et al., 2005).

2-Pyrones, the cyclic 6-membered esters are the natural isolates obtained from the extracts of plants, bacteria and other animals by using conventional chromatography (Jensen and Fenical, 1994; Faulkner, 2001). Their role in providing protection to the organisms against various other attackers is well established (McGlacken and Fairlamb, 2005). The dihydro-2-pyrones isolated from microbial sources have shown a diverse range of biological activities. Some of their activities include anticancer, anti-HIV, antifungal, neurotoxic, cytotoxic, phytotoxic, and activities (Dickinson, 1993, Thaisrivongs et al., 1996; Poppe et al., 1997; Turner et al., 1998). The mechanism of anticancer activity of 2-pyrones involves inhibition of DNA synthesis in the cells (Trachootham et al., 2008). In the human leukemic cells, 2-pyrones have been shown to inhibit cell growth 
through suppression of DNA synthesis (Trachootham et al., 2008).

The present study was performed to investigate the effect of 5-bromo-3-(3-hydroxyprop-1-ynyl)-2H-pyran2-one (BHP), an analog of 2-pyrone, in the inhibition of cell growth and induction of apoptosis in the prostate cancer cells.

\section{Materials and Methods}

\section{Chemicals and reagents}

BHP and DMEM was obtained from Sigma-Aldrich (St. Louis, MO). Cell viability assay kit and annexin V-FITC apoptosis detection kit were purchased from Santa Cruz Biotechnology (USA). The other common chemicals were purchased from Sigma-Aldrich (St. Louis, $\mathrm{MO})$.

\section{Cell lines and cell culture}

PC3 cell line was obtained from Korean Cell Line Bank (South Korea) and cultured in DMEM medium supplemented with $10 \%$ fetal bovine serum. The cells were maintained at $37^{\circ} \mathrm{C}, 5 \% \mathrm{CO}_{2}$ environment.

\section{Cell proliferation assays}

For the determination of cell viability MTT $[12 \mu \mathrm{L}, 5$ $\mathrm{mg} / \mathrm{mL}$ in phosphate buffered saline (PBS)] assay was used. PC3 cells were grown in DMEM supplemented with 10\% FBS and cultured in an incubator with humidified atmosphere of $5 \% \mathrm{CO}_{2}$ at $37^{\circ} \mathrm{C}$. The cells were dispersed on to 96-well plates at a density of $2.5 \mathrm{x}$ $10^{5}$ cells per well. To each of the well different concentrations of BHP were added and incubated for 48 hours where as the untreated and control cells were treated with DMSO. After incubation, MTT reagent (Sigma-Aldrich) was added to each of the well and incubation was continued for 4 hours more. The contents dissolved in dimethyl sulfoxide were subjected to the measurement of absorbance at $455 \mathrm{~nm}$ wavelength using an ELISA reader (BD Biosciences, USA).

\section{Determination of apoptosis by fluorescent microscopy}

For the purpose of determination of apoptosis in PC3 cells annexin V-FITC apoptosis detection kit was used. The apoptotic cells were differentiated from the necrotic cells by using propidium iodide staining. PC3 cells were allowed to attach on to the culture glass slides and then the cells were exposed to BHP. Following 48 hours of incubation with BHP the cells were treated with $1 \mathrm{X}$ binding buffer, annexin V-FITC and propidium iodide reagents. After incubation for $20 \mathrm{~min}$ at $37^{\circ} \mathrm{C}$ under dark conditions fluorescent microscopy (Leica Microsystems $\mathrm{GmbH}$, Germany) was used to analyze the apoptotic cells.

\section{Tube formation assay}

In order to determine the tube formation property, polarization of the matrigel (BD Biosciences, USA) was performed at $37^{\circ} \mathrm{C}$ for $40 \mathrm{~min}$. HUVECs at a density of $2.5 \times 10^{5}$ cells per $\mathrm{ml}$ were put in ECGM2 medium supplemented with $50 \mathrm{ng} / \mathrm{mL}$ VEGF. The cell suspension $(0.2 \mathrm{~mL})$ was put in to each of the matrigel-coated well and treated with BHP or DMSO as control for 24 hours. The phase-contrast microscope was used to examine the alteration in the morphology and formation of tubes whereas the images were captured at magnification $\times 200$.

\section{Cell invasion and motility assay}

The invasive ability of the tumor cells was determined using matrigel invasion chamber. The membranes composed of polycarbonate bearing $8 \mu \mathrm{m}$ sized pores were coated with matrigel $\left(10 \mu \mathrm{g} / \mathrm{cm}^{2}\right)$ and then incubated overnight. The BHP treated cells after incubation for 48 hours were put in the upper chamber at a density of 2.5 $x 10^{6}$ cells in RPMI-1640 supplemented with $1 \%$ BSA. The lower chamber used as a chemoattractant contained RPMI-1640 medium supplemented with 10\% FBS. Following 24 hours incubation, the membranes were fixed in $4 \%$ paraformaldehyde. After $30 \mathrm{~min}$ the membranes were stained with eosin washed with PBS and removed from the inserts. The membranes were cleared from the upper side and membranes were mounted using glycerol. For the calculation of invaded cells five regions were randomly selected and the cells were calculated three times in each region.

\section{Western blot analysis}

The BHP treated cells were washed three times with cold PBS and then treated with $120 \mu \mathrm{L}$ radioimmunoprecipitation assay buffer $[50 \mathrm{mM}$ Tris $-\mathrm{HCl}, \mathrm{pH}$ 6.8; $0.1 \%$ SDS, $150 \mathrm{mM} \mathrm{NaCl}, 1 \mathrm{mM}$ EDTA, $0.1 \mathrm{mM}$ Na3VO4, $1 \mathrm{mM}$ sodium fluoride $(\mathrm{NaF}), 1 \%$ Triton $\mathrm{X}-100,1 \% \mathrm{NP}-40,1 \mathrm{mM}$ dithiothreitol, $1 \mathrm{mM}$ PMSF, 1 $\mu \mathrm{g} / \mathrm{mL}$ aprotinin, $1 \mu \mathrm{g} / \mathrm{mL}$ leupeptin and $1 \mu \mathrm{g} / \mathrm{mL}$ pepstatin A]. The cell lysates were collected into $1.5-\mathrm{mL}$ culture tubes and then centrifuged at $12,000 \times \mathrm{g}$ for 30 min to collect the supernatants. Bicinchoninic acid assay (Sigma-Aldrich) was used for the determination of concentration of proteins. Electrophoresis on $10 \%(\mathrm{w} / \mathrm{v})$ SDS-polyacrylamide gel was used for the isolation of the proteins. The proteins were then transferred onto polyvinylidene difluoride membranes which were blocked with $5 \%$ skimmed milk in buffer [ $10 \mathrm{mM}$ Tris$\mathrm{HCl}$ (pH 7.6), $100 \mathrm{mM} \mathrm{NaCl}$ and $0.1 \%$ (v/v) Tween-20]. Incubation of the membranes with primary antibodies was performed overnight. The membranes were washed with Tris-buffered saline and Tween-20 followed by incubation with the secondary antibodies for 1 hour. Tanon Gel Imager system (Tanon, China) was used for the semi-quantitative analysis of the proteins.

\section{Real-time quantification PCR}

A total of $2.5 \times 10^{6}$ cells in $100-\mathrm{mm}$ dishes were treated 
with BHP for 48 hours followed by cell lysis. The RNeasy Plus Mini kit (Qiagen, USA) was used to extract the cell RNA and Superscript III First-strand Synthesis Super Mix for qRT-PCR (Invitrogen, USA) for RT-PCR. The NanoDrop1000 (Thermo Fisher Scientific, USA) was used for the determination of concentration of cDNA. For PCR an initial incubation was performed at $50^{\circ} \mathrm{C}$ for $2 \mathrm{~min}$, then denaturation at $95^{\circ} \mathrm{C}$ for $10 \mathrm{~min}$ followed by 50 cycles of $95^{\circ} \mathrm{C}$ for $15 \mathrm{sec}$ and $60^{\circ} \mathrm{C}$ for 1 min. The expression level of HMGB1, IL-6, IL-8 and (NAG-1) genes was analyzed using a SYBR green based gene specific real-time PCR quantification kit (SA Biosciences).

\section{Statistical analysis}

$\mathrm{Al}$ the data were analyzed using ANOVA and StudentNewman-Keuls test. The results expressed the mean \pm SD. $\mathrm{p}<0.05$ was considered statistically significant.

\section{Results}

\section{Effect on the growth and proliferation of PC3}

Examination of the effect of BHP on the rate of cell proliferation in PC3 and DU-145 cells showed a concentration and time dependent inhibition. Increase in the concentration of BHP from 10 to $40 \mu \mathrm{M}$ significantly increased the inhibition of cell growth. The inhibition of cell proliferation in PC3 and DU-145 cells at $40 \mu \mathrm{M}$ concentration of $\mathrm{BHP}$ was 76 and $74 \%$, respectively after 48 hours (Figure 1).

\section{Effect on the induction of apoptosis in PC3 cells}

The results from annexin V-FITC and propidium iodide staining showed a concentration dependent effect of BHP on apoptosis in PC3 cells after 48 hours (Figure 2). With the increase in concentration of BHP from 10 to 40 $\mu \mathrm{M}$, the proportion of apoptotic cells increased from 12
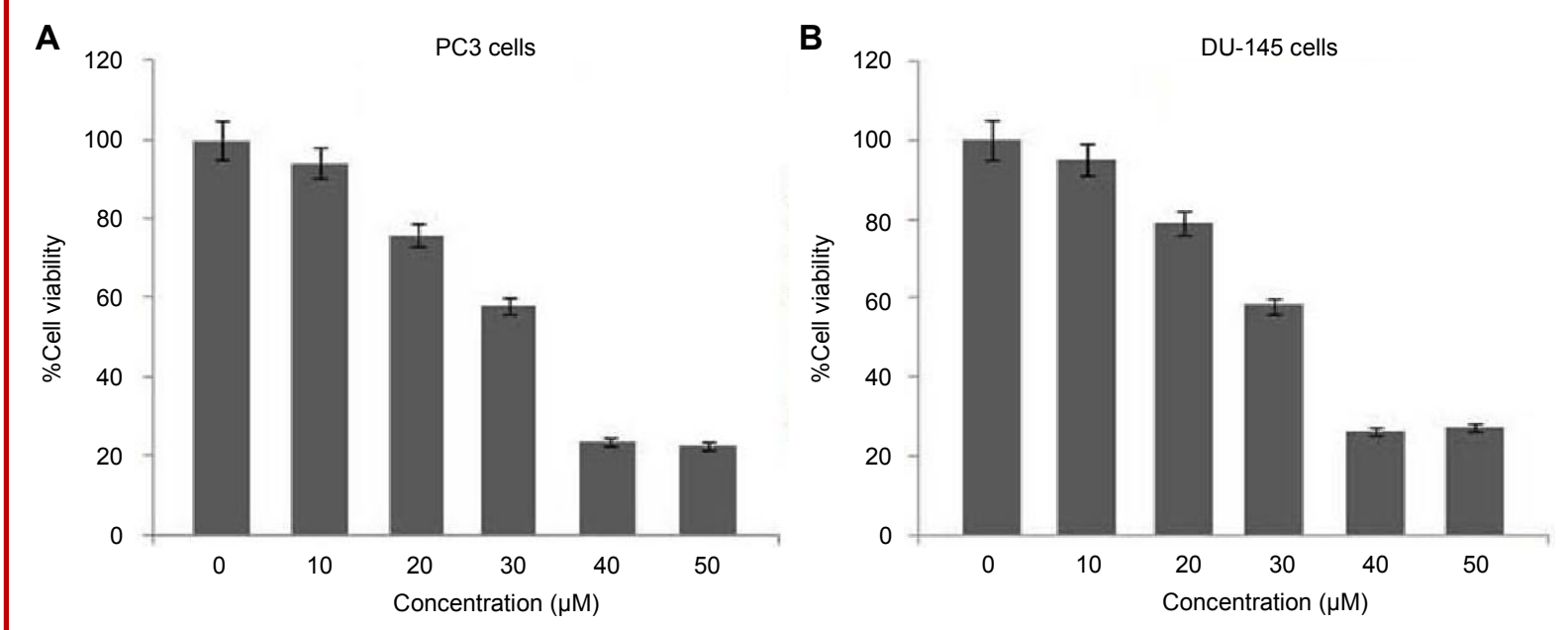

Figure 1: Effect of BHP on inhibition of proliferation in PC3 and DU-145 cells. The viability of the cells was determined by MTT assay. BHP caused significant reduction in the viability of PC 3 and DU-145 cell lines

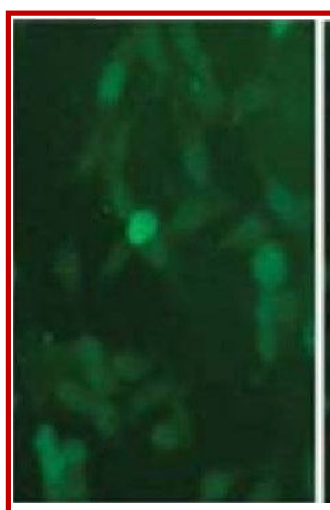

DMSO

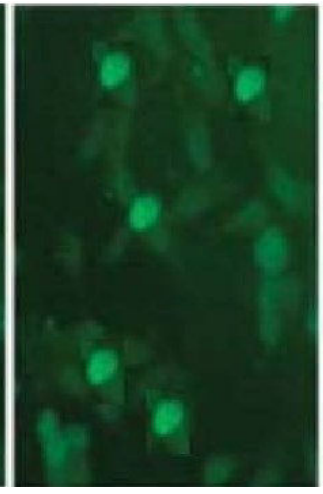

10

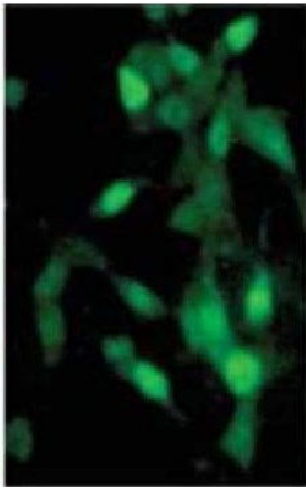

20

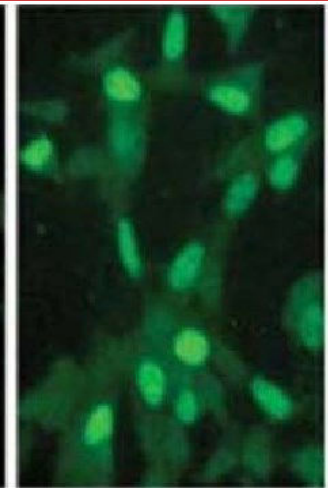

30

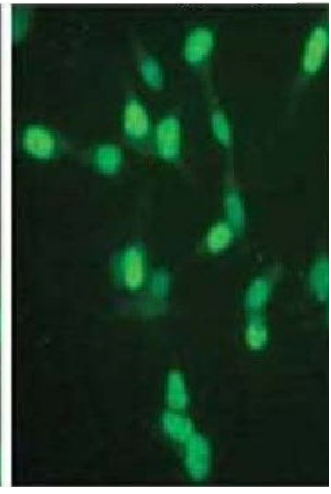

40

Concentration of $\mathrm{BHP}(\mu \mathrm{M})$

Figure 2: BHP treatment induces apoptosis in PC3 prostate carcinoma cells. PC3 cells after incubation with BHP or DMSO as control for 48 hours were stained using annexin V-FITC and propidium iodide. The fluorescence microscopy was used for the visualization of apoptotic cells 
to $62 \%$. The increase in the proportion of apoptotic cells on enhancing the concentration of BHP was further confirmed by flow cytometry analyses (Figure 3).

\section{Effect on the tube formation of HUVEC and invasive ability of PC3 cells}

Examination of the effect of BHP on tube formation of HUVEC cultured with BHP treated PC3 prostate cancer revealed marked inhibition in tube formation on matrigel (Figure 4). On the other hand, HUVEC cultured with control PC3 prostate cancer cells showed extensive formation of tubes. The results from matrigel trans well assay revealed that BHP treatment in PC3 cells caused a significant decrease in the percentage of cells penetrating through matrigel coated transwell filters.

\section{Effect on the expression of p65, VEGF and MMP-9 in PC3 cells}

The process of angiogenesis and the ability of cancer cells to invade other tissues is controlled and regulated by NF-kB (p65), VEGF and matrix metallo-proteinase- 9

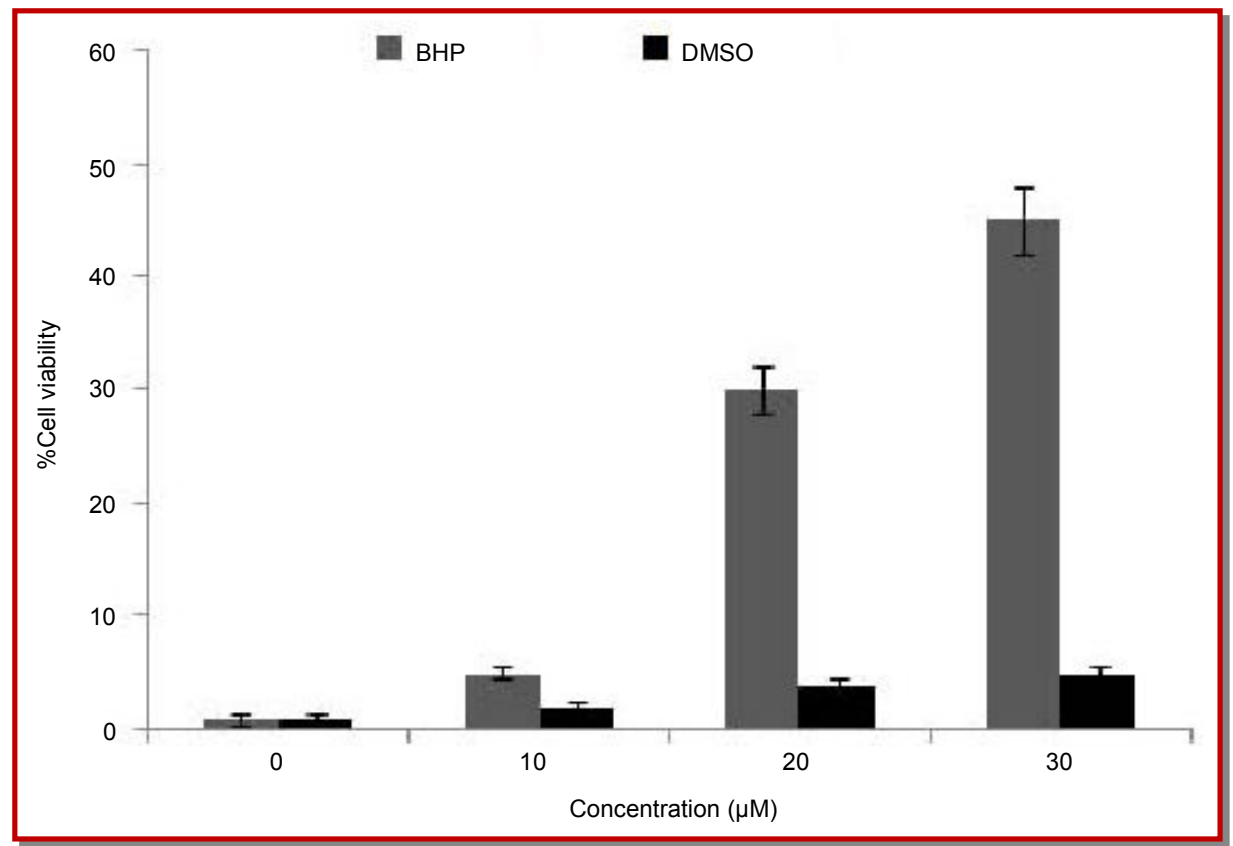

Figure 3: BHP treatment induces cell death in PC3 prostate carcinoma cells. PC3 cells treated with BHP for 48 hours followed by PI staining and flow cytotmetry analysis

\section{A}

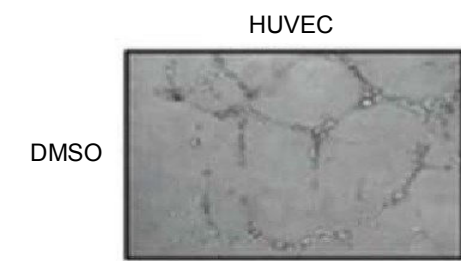

$\mathrm{BHP}$

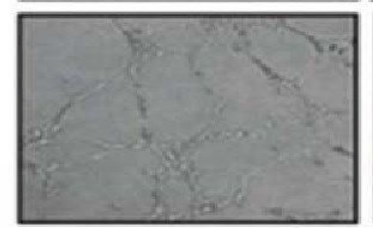

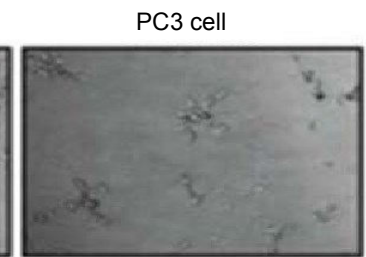

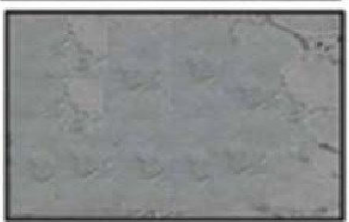

B

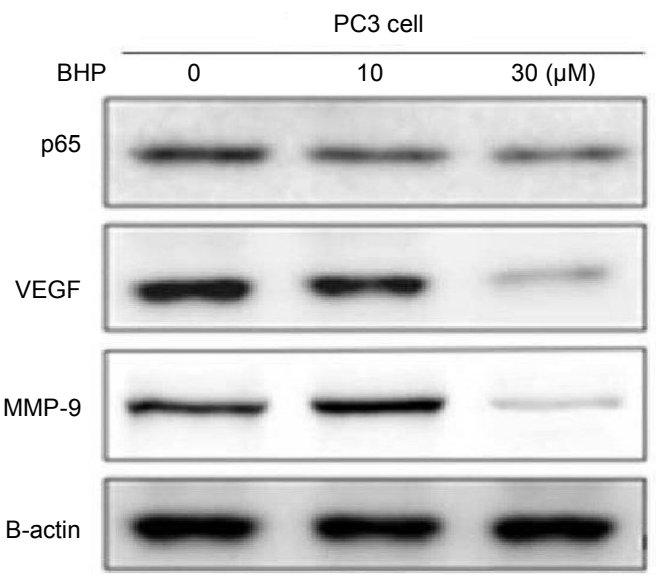

Figure 4: BHP exposure inhibited HUVEC tubulogenesis and PC3 cell invasion. (A) BHP influences tube formation by the endothelial cells through involvement of angiogenic factors in PC3 cells. PC3 cells cultured in the presence of BHP on matrigel precoated transwells plates for 24 hours showed inhibition in invasive ability on matrigel. (B) PC3 cells exposed to BHP for 24 hours showed inhibition in the expression of p65, VEGF and MMP-9 by immunoblot analysis 


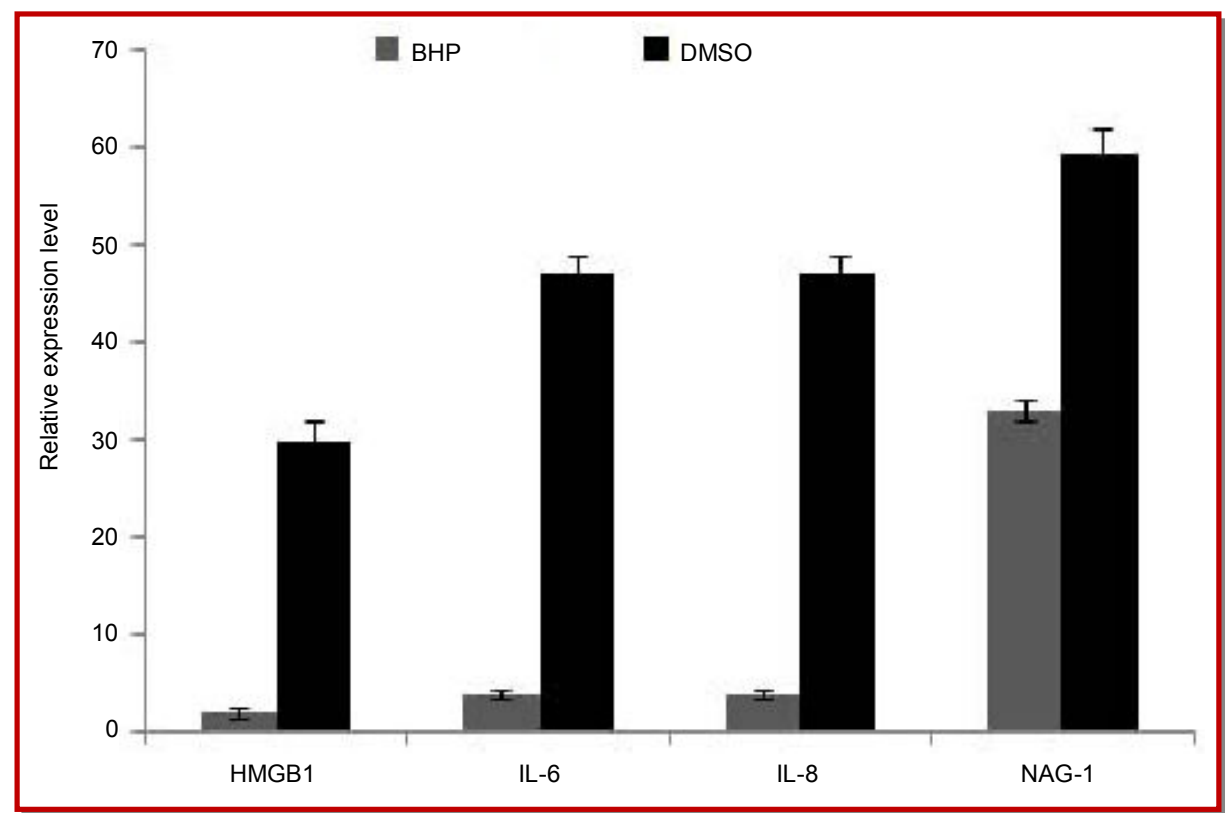

Figure 5: Inhibition of HMGB1, IL-6 and IL-8 expression and promotion of NAG-1 expression by BHP treatment in PC3 cells. The PC 3 cells were incubated with BHP or DMSO as the control for 48 hours at $37^{\circ} \mathrm{C}$. After incubation, expression levels of $\mathrm{HMGB1}$, IL -6, IL-8 and NAG-1 genes were quantified by real-time PCR

(MMP-9). Results from the immune blot analysis showed that exposure of PC3 cells to BHP significantly inhibited the p65, VEGF and MMP-9 expression levels compared to the control cells.

\section{Effect on the expression of inflammatory genes}

The results from the quantitative real-time RT-PCR analysis revealed that $\mathrm{BHP}$ treatment in PC3 cells decreased the HMGB1, IL-6, and IL-8 expression levels and promoted the NAG-1 expression compared to the control cells (Figure 5).

\section{Discussion}

The results from our study using annexin $\mathrm{V}$ binding revealed that BHP inhibited cell proliferation through apoptotic cell death. The metastases of the carcinoma cells to the distant tissues are promoted by the processes like angiogenesis and invasion (Weidner et al., 1993; Wakui et al., 1992). The results from the present study showed that BHP treatment inhibited the invasive property and angiogenesis in PC3 cells. BHP treatment also caused inhibition in the expression of p65, VEGF and MMP-9. Thus, the inhibition of invasive property and angiogenesis in the PC3 cells by BHP involves reduction in the expression of p65, VEGF and MMP-9. Thus, BHP can be a promising candidate for the treatment of prostate carcinoma.

The factors like cytokines and chemokines are responsible for the creation of feasible environment for progress of the cancer. Inflammation is associated with facilitating the progress of cancer ( $\mathrm{Lu}$ et al., 2002; Coussens and Werb, 2002). The patients with hormone resistant disease show higher concentration of IL-6 and IL-8 in the serum (Veltri et al., 1999; Pfitzenmaier et al., 2003; Uehara et al., 2005). The results from the present study demonstrated that $\mathrm{BHP}$ treatment inhibited the expression of HMGB1, IL-6 and IL-8 in PC3 cells. Reduction in the expression of HMGB1 has been reported to induce apoptosis in the prostate cancer cell (Gnanasekar et al., 2009).

\section{Conclusion}

BHP treatment inhibits the cell proliferation, induces apoptosis, inhibits the tube formation and invasive ability of the prostate carcinoma cells.

\section{References}

Coussens LM, Werb Z. Inflammation and cancer. Nature 2002; 420: 860-67.

Dickinson JM. Microbial pyran-2-ones and dihydropyran-2ones. Nat Prod Rep. 1993; 10: 71-98.

Faulkner DJ. Marine natural products. Nat Prod Rep. 2001; 18: 1-49.

Gnanasekar M, Thirugnanam S, Ramaswamy K. Short hairpin RNA (shRNA) constructs targeting high mobility group box1 (HMGB1) expression leads to inhibition of prostate cancer cell survival and apoptosis. Int J Oncol. 2009; 34: 425-31.

Jemal A, Siegel R, Xu J, Ward E. Cancer statistics, 2010. CA 


\section{Cancer J Clin. 2010; 60: 277-300.}

Jensen PR, Fenical W. Strategies for the discovery of secondary metabolites from marine bacteria: Ecological perspectives. Annu Rev Microbiol. 1994; 48: 559-84.

Lu H, Ouyang W, Huang C. Inflammation, a key event in cancer development. Mol Cancer Res. 2006; 4: 221-33.

McGlacken GP, Fairlamb IJ. 2-Pyrone natural products and mimetics: Isolation, characterisation and biological activity. Nat Prod Rep. 2005; 22: 369-85.

Pfitzenmaier J, Vessella R, Higano CS, Noteboom JL, Wallace D Jr, Corey E. Elevation of cytokine levels in cachectic patients with prostate carcinoma. Cancer 2003; 97: 1211-16.

Poppe SM, Slade DE, Chong KT, Hinshaw RR, Pagano PJ, Markowitz M, Ho DD, Mo H, Gorman RR 3rd, Dueweke TJ, et al., Antiviral activity of the dihydropyrone PNU-140690, a new non-peptidic human immunodeficiency virus protease inhibitor. Antimicrob Agents Chemother. 1997; 41: 1058-63.

Thaisrivongs S, Romero DL, Tommasi RA, Janakiraman MN, Strohbach JW, Turner SR, Biles C, Morge RR, Johnson PD, Aristoff PA, et al., Structure-based design of HIV protease inhibitors: 5,6-dihydro-4-hydroxy-2-pyrones as effective, non -peptidic inhibitors. J Med Chem. 1996; 39: 4630-42.
Trachootham D, Lu W, Ogasawara MA, Nilsa RD, Huang P. Redox regulation of cell survival. Antioxid Redox Signal. 2008; 10: 1343-74.

Turner SR, Strohbach JW, Tommasi RA, Aristoff PA, Johnson PD, Skulnick HI, Dolak LA, Seest EP, Tomich PK, Bohanon MJ, et al., Tipranavir (PNU-140690): A potent, orally bioavailable non-peptidic HIV protease inhibitor of the 5,6dihydro-4-hydroxy-2-pyrone sulfonamide class. J Med Chem. 1998; 41: 3467-76.

Uehara $\mathrm{H}$, Troncoso $\mathrm{P}$, Johnston D, et al. Expression of interleukin-8 gene in radical prostatectomy specimens is associated with advanced pathologic stage. Prostate 2005; 64: 40-49.

Veltri RW, Miller MC, Zhao G, et al., Interleukin-8 serum levels in patients with benign prostatic hyperplasia and prostate cancer. Urology 1999; 53: 139-47.

Wakui S, Furusato M, Itoh T, et al. Tumour angiogenesis in prostatic carcinoma with and without bone marrow metastasis: A morphometric study. J Pathol. 1992; 168: 257-62.

Weidner N, Carroll PR, Flax J, Blumenfeld W, Folkman J. Tumor angiogenesis correlates with metastasis in invasive prostate carcinoma. Am J Pathol. 1993; 143: 401-09.

\section{Author Info \\ I Jun-Hao Niu (Principal contact) \\ e-mail: niujunhaoqwe@hotmail.com \\ , First two authors contributed equally}




\section{Your feedback about this paper}

1. Number of times you have read this paper 0

2. Quality of paper

$\bigcirc$ Excellent $\bigcirc$ Good $\bigcirc$ Moderate $\bigcirc$ Not good

3. Your comments

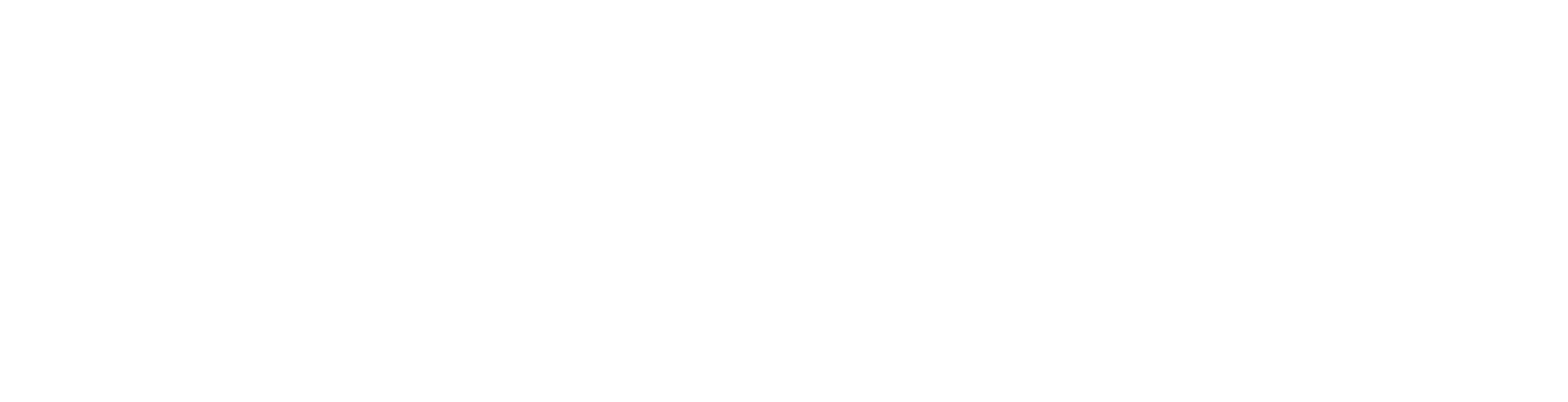

